\title{
High-Selectivity Single-Chip Spectrometer for Operation at Visible Wavelengths
}

\author{
J. H. Correia*, M. Bartek and R. F. Wolffenbuttel \\ Delft University of Technology, ITS/Electrical Engineering, \\ Lab. for Electronic Instrumentation/DIMES, 2628 CD Delft, The Netherlands
}

\begin{abstract}
A micro-spectrometer has been realized based on an array of Fabry-Perot thin-film optical resonators. The 16 channel micro-spectrometer is IC fabrication compatible and operates in the visible spectral range with an inter-channel shift of $6 \mathrm{~nm}$. Each of the channels is sensitive in a single peak with FWHM of $16 \mathrm{~nm}$. A FWHM $<2 \mathrm{~nm}$ and finesse of 40 for narrowband operation is demonstrated.
\end{abstract}

\section{Introduction}

Numerous applications, e.g. systems for chemical analysis by optical absorption and emission line characterization, will benefit from the availability of low-cost single-chip spectrometers. Miniaturized spectrometers will offer significant advantages over existing instruments, including size reduction, low cost, fast data-acquisition and high reliability. Previously developed micro-spectrometers [1-5], fabricated using bulk or surface micromachining, contain movable parts to perform wavelength tuning. As a result, these are less reliable and suitable only for operation in a limited spectral band (mostly near-IR) [5-6]. Moreover, high-voltage electrostatic actuation is necessary for resonance cavity tuning.

Operation in the visible spectral range (with transmission in a single peak) requires cavity length below $500 \mathrm{~nm}$. Fabrication and modulation of a such narrow airgap between the two mirrors is severally hindered by capillary forces inside of the cavity. Also, electrostatic pull-in and subsequent sticking of the two mirrors limits the operating range of the device to one third of the initial air gap [7].

\section{Micro-Spectrometer Design}

We have developed a new single-chip Fabry-Perot arraytype micro-spectrometer suitable for the visible spectral range which does not require electrostatic actuation. The realized device, schematically shown in Fig. 1 (an individual channel in cross-section) and Fig. 2 (the complete $4 \times 4$ array micro-spectrometer), is fully fabrication compatible with a standard IC processing.

*On leave from University of Minho, Dept. of Industrial Electronics, Portugal, Grant \#FCT-Program Praxis XXI-BD/5181/95.

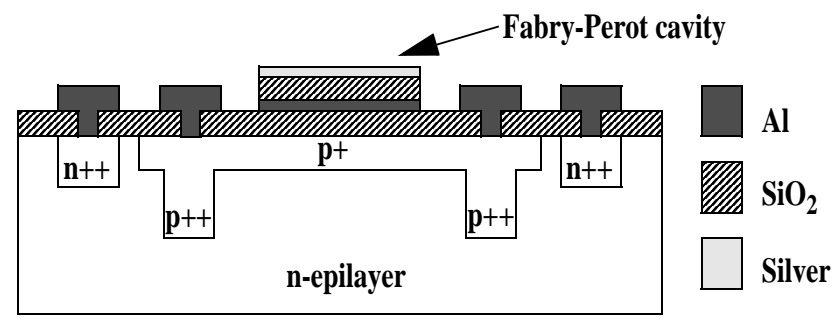

Fig.1: Schematic structure of the micro-spectrometer: individual channel in cross-section.

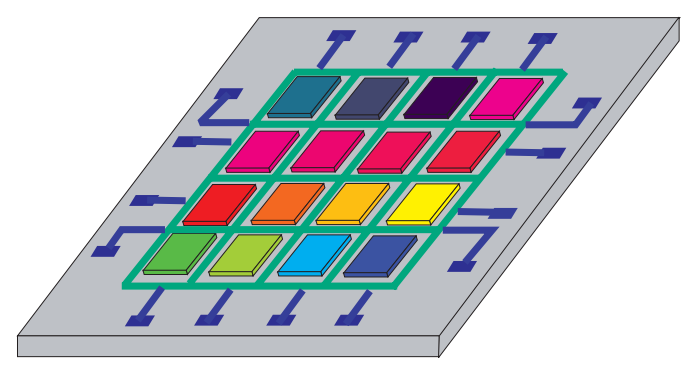

Fig. 2: A 4x4 array micro-spectrometer in perspective. Each of the Fabry-Perot cavities is tuned to transmit in different spectral band.

The impinging spectrum is filtered in the Fabry-Perot resonator and the intensity of the selected spectral component is measured in transmission using an underlying integrated photodiode array. On top of each photodiode an $\mathrm{Al} / \mathrm{SiO}_{2} / \mathrm{Ag}$ layer stack is deposited functioning as the Fabry-Perot optical filter. The thickness of the PECVD silicon dioxide layer, which is enclosed inbetween two semi-transparent metallic mirrors, determines the wavelength tuned to. In N subsequent plasma etching steps (using different photoresist masks), the initially deposited PECVD oxide layer is thinned forming $2^{\mathrm{N}}$ channels, each with different resonance cavity length. An oxide layer is present between the cavity and the photodiode and introduces a wavelength-dependent transmission of the incident radiation. Its thickness was designed for a flat transmittance over the visible spectra range [8-9]. Evaporated metallic mirrors were used instead of high-performance dielectric mirrors, to maintain fabrication simplicity (only one layer must be deposited). 
Another advantage of metallic mirrors is the suitability for use over a wide spectral range [10]. Silver and aluminum have been selected for high reflectivity at visible wavelengths (see Fig. 3). Fabry-Perot filters using metallic mirrors cannot provide both high finesse (ratio between the free spectral range and Full-Width-Half-Maximum, FWHM) and high transmittance simultaneously due to the optical absorption in the metal layers (Fig. 4). Unlike macroscopic applications of silver-based reflective coatings [11], the poor environmental resistance of silver is not critical in a microsystem application. Sealing of a complete system avoids any environmentally caused mirror degradation.

A thin-film optics software package was used to perform optimization of the FP filter. The transmittance for a $60 \mathrm{~nm}$ $\mathrm{Ag} / 1000 \mathrm{~nm}-\mathrm{SiO}_{2} / 60 \mathrm{~nm}-\mathrm{Ag}$ layer stack (Fig. 5) shows FWHM of $1.8 \mathrm{~nm}$ and finesse of 40. The Ag layer thickness is a trade-off between achievable FWHM and absorption loss. For fabrication compatibility reasons, Al layer was used for the bottom mirror. Due to higher absorption in $\mathrm{Al}$ (when compared to $\mathrm{Ag}$ ), the performance slightly decreases as shown in Fig. 6 (a FWHM of $6 \mathrm{~nm}$ for a finesse of 12).

\section{Device Fabrication}

Photodiode array is fabricated using a standard IC processing (bipolar or CMOS). Fabry-Perot etalons are added in a post-processing module. Firstly, a $20 \mathrm{~nm}$ Al layer is evaporated and patterned using lift-off. Then a PECVD oxide layer is deposited with thickness equal to the maximum cavity length. Subsequently, $\mathrm{N}$ plasma etching steps are used to form $2^{\mathrm{N}}$ different thicknesses of the oxide layer. Thickness accuracy better than $2 \mathrm{~nm}$ was achieved. Silver layer is deposited in the very end of the fabrication sequence and patterned using lift-off. Fig. 7 shows a photograph of the fabricated device with overall dimensions of $4.7 \times 4.7 \mathrm{~mm}^{2}$.

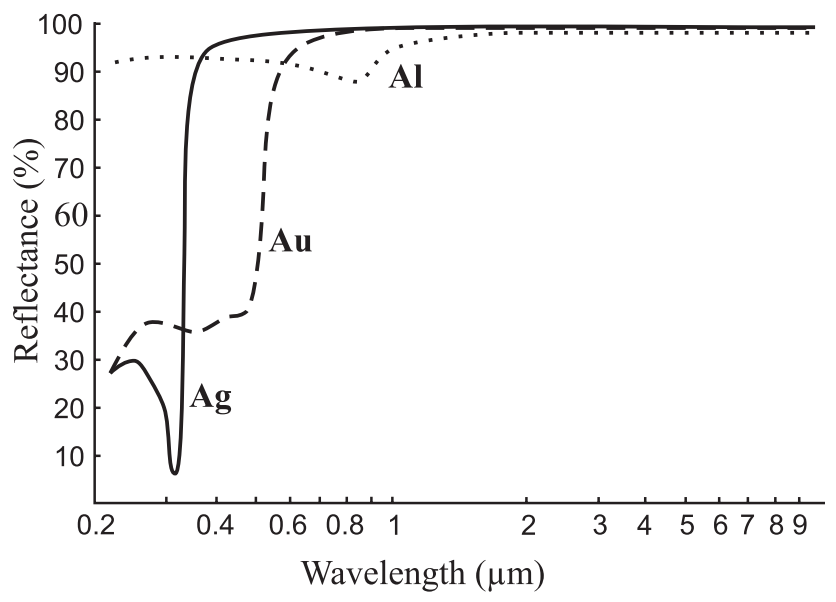

Fig. 3: Reflectance of $\mathrm{Ag}, \mathrm{Au}$ and $\mathrm{Al}$ as a function of radiation wavelength [10].

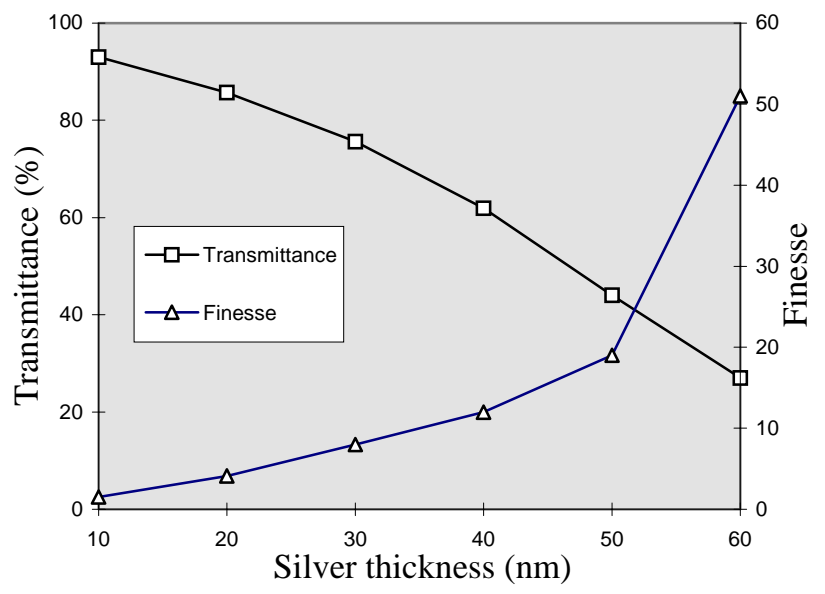

Fig. 4: Transmittance and finesse as a function of silver thickness.

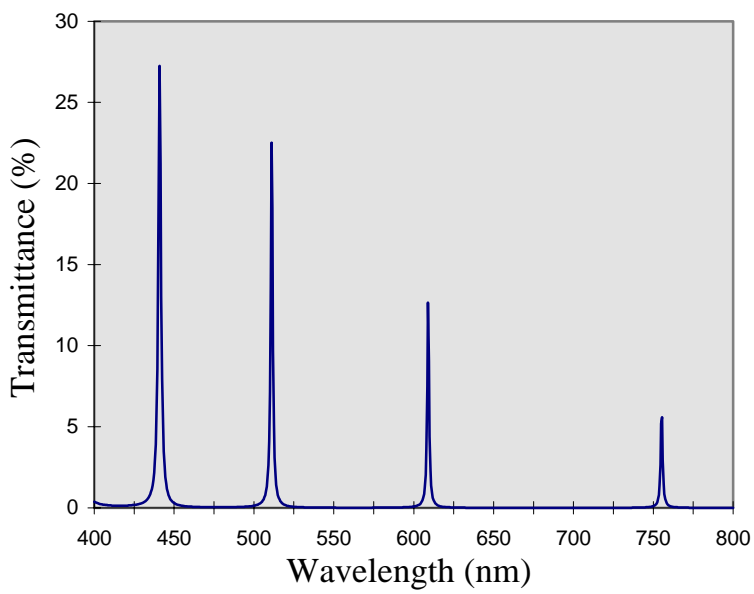

Fig. 5: Simulated transmittance vs. wavelength for $60 \mathrm{~nm} \mathrm{Ag} \mathrm{/} 1000 \mathrm{~nm}$ $\mathrm{SiO}_{2} / 60 \mathrm{~nm} \mathrm{Ag}$ layer stack.

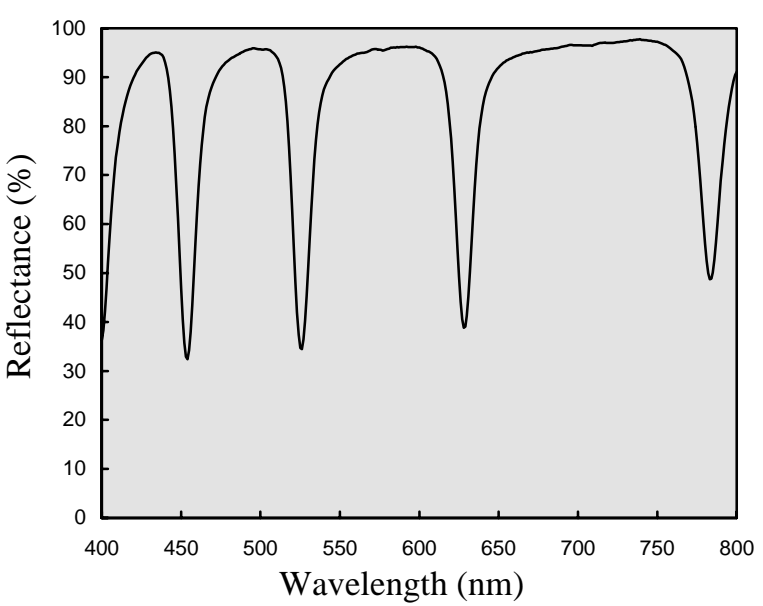

Fig. 6: Measured reflectance vs. wavelengths for a $45 \mathrm{~nm} \mathrm{Ag} / 1000 \mathrm{~nm}$ $\mathrm{SiO}_{2} / 20 \mathrm{~nm}$ Al layer stack. 


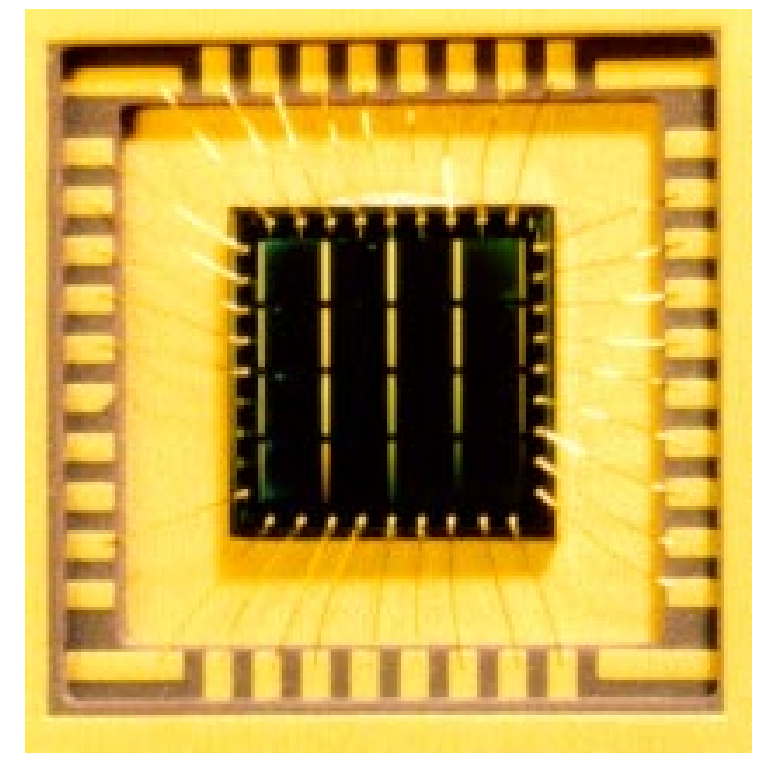

Fig. 7: Photograph of the fabricated micro-spectrometer with $4 \times 4$ channels. The die area is $4.7 \times 4.7 \mathrm{~mm}^{2}$.

\section{Experimental Results}

The electrical characteristics and spectral responsivity were measured using an HP4142B DC Source/Monitor (full-scale range from $10^{-15} \mathrm{~A}$ to $1 \mathrm{~A}$ and a resolution of $10^{-13} \mathrm{~A}$ ). A $100 \mathrm{~W}$ quartz tungsten halogen lamp with a monochromator TRIAX-180 (1200 g/mm grating with a spectral dispersion of $3.6 \mathrm{~nm} / \mathrm{mm}$ and a spectral resolution of $0.3 \mathrm{~nm}$ at $546 \mathrm{~nm}$ ), was used as the light source. A collimator lens was used to image the light on the entrance slit. At the exit slit a pinhole and a focusing lens were used to achieve a beam with a diameter of about $400 \mu \mathrm{m}$ [12]. The measurements were calibrated with a commercial photodiode Hamamatsu S1336-5BQ.

System operation is demonstrated on a 16 channel microspectrometer designed to be sensitive in the spectral range between 400 to $500 \mathrm{~nm}$ with inter-channel shift of about $6 \mathrm{~nm}$. Each of the channels consists of a $20 \mathrm{~nm}-\mathrm{Al} / \mathrm{SiO}_{2} /$ $45 \mathrm{~nm}$-Ag layer stack, where oxide layer thickness changes between $220 \mathrm{~nm}$ and $300 \mathrm{~nm}$ with $5 \mathrm{~nm}$ steps. Optical spectral measurements (using an external detector) show (see Fig. 8) that each of the channels is sensitive to only one narrow spectral band with FWHM of $16 \mathrm{~nm}$ over the entire visible spectral range (400 to $780 \mathrm{~nm}$ ).

Subsequently, measurements were performed on the device with integrated photodiodes shown in Fig. 7. A dark current of $0.2 \mathrm{pA}$ at $0 \mathrm{~V}$ and $1 \mathrm{pA}$ at $-4 \mathrm{~V}$ (see Table 1) was measured for a photodiode active area of $1 \mathrm{~mm}^{2}$. The overall device performance is a trade-off between sensitivity, selectivity and the number of channels used. An increased
Ag-layer thickness improves selectivity but causes higher absorption losses and, therefore, sensitivity, is decreased. For $45 \mathrm{~nm}-\mathrm{Ag}$ and 20nm-Al layers used, a maximum transmittance of about $15 \%$ was measured.

Fig. 9 presents the spectral responsivity (A/W) between $400 \mathrm{~nm}$ to $800 \mathrm{~nm}$ for all 16 channels using on-chip photodiodes. The ratio between the base line and the peak maximum ranges from 4 to 7 . Large variations (comparing with Fig. 8) in the height of the peaks is due to: the spectral sensitivity of the integrated photodiodes and the relatively high stray light sensitivity (no optical shielding between the individual Fabry-Perot channels was used).

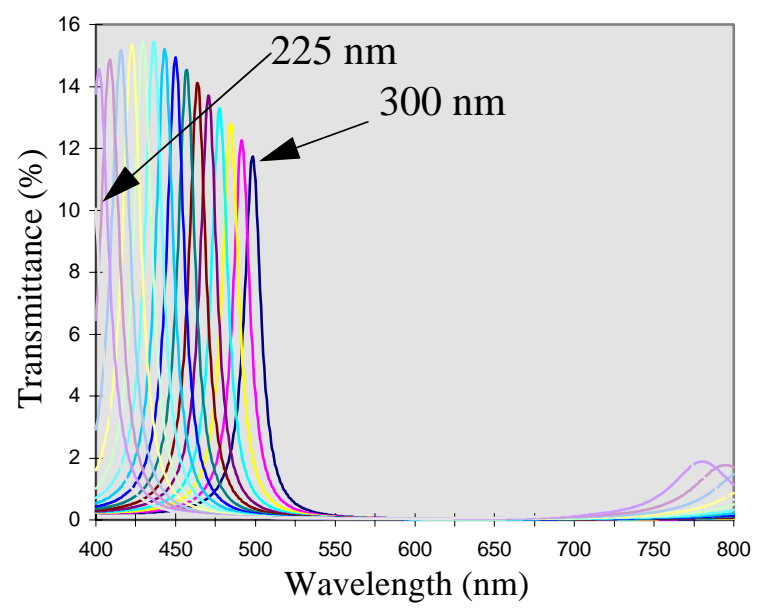

Fig. 8: Measured transmittance vs. wavelength for $45 \mathrm{~nm} \mathrm{Ag} / \mathrm{SiO}_{2} / 20 \mathrm{~nm}$ Al layer stack. The $\mathrm{SiO}_{2}$ layer thickness is used as a parameter and changes from $225 \mathrm{~nm}$ to $300 \mathrm{~nm}$ in $5 \mathrm{~nm}$ increments.

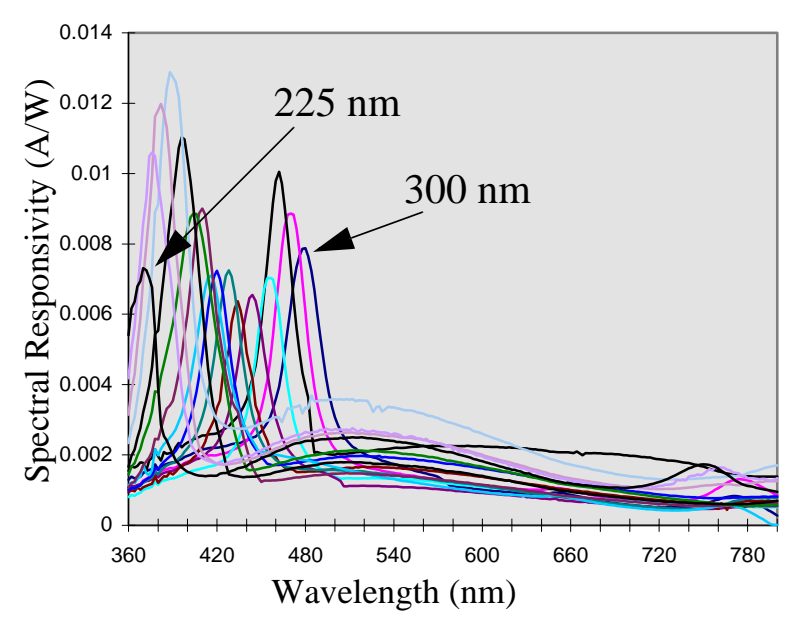

Fig. 9: Spectral responsivity of the 16 channel micro-spectrometer for a $45 \mathrm{~nm} \mathrm{Ag} / \mathrm{SiO}_{2} / 20 \mathrm{~nm} \mathrm{Al}$ layer stack. The $\mathrm{SiO}_{2}$ layer thickness is used as a parameter and changes from $225 \mathrm{~nm}$ to $300 \mathrm{~nm}$ in $5 \mathrm{~nm}$ increments. 


\section{Acknowledgments}

Table 1: Electrical and optical characteristics

\begin{tabular}{|c|c|}
\hline Feature & Result \\
\hline Technology & Bipolar or CMOS \\
\hline Device area & $4.7 \times 4.7 \mathrm{~mm}^{2}$ \\
\hline $\begin{array}{l}\text { FWHM } \\
@ \mathrm{t}_{\mathrm{SiO} 2}=300 \mathrm{~nm}\end{array}$ & $16 \mathrm{~nm}$ \\
\hline $\begin{array}{l}\text { Finesse } \\
@ \mathrm{t}_{\mathrm{SiO} 2}=300 \mathrm{~nm}\end{array}$ & Single peak \\
\hline $\begin{array}{l}\text { FWHM (simulated) } \\
@ 60 \mathrm{~nm} \text { Ag mirrors } \\
@ \mathrm{t}_{\mathrm{SiO} 2}=1 \mu \mathrm{m}\end{array}$ & $1.8 \mathrm{~nm}$ \\
\hline $\begin{array}{l}\text { Finesse (simulated) } \\
@ 60 \mathrm{~nm} \mathrm{Ag} \mathrm{mirrors} \\
@ \mathrm{t}_{\mathrm{SiO} 2}=1 \mu \mathrm{m}\end{array}$ & 40 \\
\hline Dark current@0V & $0.2 \mathrm{pA}$ \\
\hline Dark current@-4 V & $1 \mathrm{pA}$ \\
\hline $\begin{array}{l}\text { Spectral response } \\
\text { maximum @-4V }\end{array}$ & 0.013 A/W@388 nm \\
\hline Incident angle range & $\pm 10^{\circ}$ \\
\hline
\end{tabular}

\section{Conclusions}

A single-chip spectrometer, combining Fabry-Perot resonance cavities on a distributed photodetectors array, was fabricated and characterized. The advantage of the device presented is that it can easily be tuned during fabrication to cover a different spectral band, by adjusting the etching time only, without affecting the device layout. Such a device is extremely suitable for applications in microsystems (e.g. $\mu$ TAS), because of its small size, high spectral selectivity and low cost. Also, micro-spectrometers for the UV and IR are feasible using this technique.

Current work aims on an entirely CMOS integrated microsystem that includes on-chip power management, signal conditioning circuits, A/D conversion and a digital bus interface for external interface.
The authors would like to thank the staff of Delft Institute of Microelectronics and Submicron Technology (DIMES), especially J. Groeneweg, for technical assistance in fabrication of the devices. This work is supported in part by STW (project DEL 55.3733), TUDelft and FCT-Portugal (Program Praxis XXI-BD/5181/95).

\section{References}

[1] J. D. Patterson and B. van Zeghbroeck,"Fabrication and analysis of Si/SiO2 Micro-mechanical Modulators", Digest IEEE/LEOS 1996 Summer topical meeting on optical MEMS and their applications, pp. 25-26, 1996.

[2] T. A. Kwa, P.M.Sarro, R.F. Wolffenbuttel, "Backside-illuminated silicon photodiode array for an integrated spectrometer", IEEE Transactions on Electron Devices, Vol. 44, No. 5, pp.761-765, May 1997.

[3] N.F. Raley, D.R. Ciarlo, J.C. Koo, B. Beiriger, J. Trujillo, C. Yu, G. Lomis, R. Chow, "A Fabry-Perot Microinterferometer for Visible Wavelength", Proc. 5th IEEE Solid State Sensor and Actuator Workshop., Hilton Head Island, SC, USA, 1992, pp. 170-173.

[4] J. H. Correia, M. Bartek, R. F. Wolffenbuttel, "Bulk-micromachined tunable Fabry-Perot microinterferometer for the visible spectral range", Proc. of Eurosensors XII, Southampton, UK, pp.287-290, September 1998.

[5] A. T. T. D. Tran, Y. H. Lo, Z. H. Zhu, D. Haronian, E. Mozdy, "Surface micromachined Fabry-Perot tunable filter", IEEE Photonics Technology Letters, Vol. 8-3, pp. 393-395, 1996.

[6] R. T. Carline, D. A. O. Hope, D. J. Robbins, M. B. Stanaway, "Vertical cavity longwave infrared $\mathrm{SiGe/Si}$ photodetector using a buried silicide mirror", Proc. of IEDM'97, Washington, USA, 1997.

[7] S. D. Senturia, Narayan Aluru, J. White, "Simulating the Behavior of MEMS Devices: Computacional Methods and Needs", IEEE Computacional Science \& Engineering, pp. 30-43, March 1997.

[8] D.P. Poenar, R.F. Wolffenbuttel, "Optical properties of thin-film silicon-compatible materials, Applied Optics", Vol. 36, No. 21, July 1997, pp. 5122-5128.

[9] R. F. Wolffenbuttel, "Photodiodes in silicon with an electricallyprogrammable UV response", Sensors and Actuators A, A22, 1990 , pp. 559-563.

[10] H.A. Macleod," Thin-film optical filters", Adam Hilger Ltd, 2nd edition, 1986

[11] D.-Y. Song, R. W. Sprague, H. A. Macleod, M. Jacobson, "Progress in the development of a durable silver-based high-reflectance coating for astronomical telescopes", Appl. Optics, Vol. 24, No. 8, 1985, pp. 1164-1170.

[12] G. M. Yee, N. I. Maluf, P. A. Hing, M. Albin, G. T. A. Kovacs, "Miniature spectrometers for biochemical analysis", Sensors and Actuators A, 58, pp.61-66, 1997. 